\title{
SorÇão do Herbicida AtraZine em Complexos Organominerais ${ }^{1}$
}

\author{
Sorption of Herbicide Atrazine in Organic-Mineral Complexes
}

\author{
PROCÓPIO, S.O. ${ }^{2}$, PIRES, F.R. ${ }^{2}$, WERLANG, R.C. ${ }^{3}$, SILVA, A.A. ${ }^{4}$, QUEIROZ, M.E.L.R. ${ }^{5}$, NEVES, \\ A.A. ${ }^{5}$, MENDONÇA, E.S. ${ }^{6}$, SANTOS, J.B. ${ }^{7}$ e EGREJA FILHO, F.B. ${ }^{8}$
}

\begin{abstract}
RESUMO - Este trabalho foi desenvolvido com o objetivo de avaliar a sorção do atrazine em complexos organominerais predominantes em solos tropicais. A amostra de herbicida utilizada na experimentação continha $97 \%$ de pureza. Alíquotas de $10 \mathrm{~mL}$ das soluções de 0,0; 10,0; 20,0; 40,0; 70,0; e 100,0 $\mu \mathrm{mol} \mathrm{L} \mathrm{L}^{-1}$ de atrazine foram adicionadas aos seguintes substratos: ácidos húmicos, caulinita, goethita, ferridrita, ácidos húmicos+caulinita, ácidos húmicos+ goethita e ácidos húmicos+ferridrita; o extrator utilizado foi o acetato de etila. As concentrações de atrazine sorvidas foram determinadas por cromatografia gasosa, com eficiência de extração de $93,67 \%$. O valor de $\mathrm{K}_{\mathrm{d}}$ encontrado $(91,89)$ para os ácidos húmicos foi cerca de nove vezes maior do que para caulinita, goethita e ferridrita isoladas e aproximadamente cinco vezes maior do que para as misturas ácidos húmicos+caulinita, ácidos húmicos+goethita e ácidos húmicos+ferridrita. As interações reduziram a sorção de atrazine pelos ácidos húmicos. A porcentagem de redução da sorção dos ácidos húmicos foi de 62,93; 65,99; e 64,63\%, quando em mistura com caulinita, goethita e ferridrita, respectivamente.
\end{abstract}

Palavras-chave: herbicida, ácidos húmicos, minerais de argila.

\begin{abstract}
This work aimed to evaluate the sorption of atrazine in organic-mineral complexes predominant in tropical soils. The atrazine sample that was used in the experiment had 97\% purity. Aliquots of $10 \mathrm{~mL}$ of atrazine solutions (0.0; 10.0; 20.0; 40.0; 70.0 and $100.0 \mu \mathrm{mol} \mathrm{L^{-1 } )}$ were added to the substrata: humic acids, kaolinite, goethite, ferrihydrite, humic acids+kaolinite, humic acids+goethite and humic acids+ferrihydrite, with the etila acetate being used as extractor. Concentrations of atrazine sorbed were determined by gas chromatography, with an extraction efficiency of $93.67 \%$. The value of $K_{d}$ found (91.89) for the humic acids was approximately nine times higher than that for kaolinite, goethite and ferrihydrite alone, and about five times higher than that for the mixtures humic acids+kaolinite, humic acids+goethite and humic acids+ferrihydrite. The interactions decreased atrazine sorption by humic acids. The humic acid sorption reduction percentage was 62.93, 65.99 and 64.63\% when mixed with kaolinite, goethite and ferrihydrite, respectively.
\end{abstract}

Key words: herbicide, humic acids, clay minerals.

\section{INTRODUÇÃO}

$\mathrm{O}$ atrazine [6-cloro-N-etil-N'-(1-metiletil)1,3,5-triazina-2,4diamina] é o herbicida mais utilizado para controle de plantas daninhas na cultura do milho em todo o mundo, podendo ser usado ainda para outras culturas, como abacaxi, cana-de-açúcar, banana, café, cacau, sorgo, chá, sisal, seringueira, maçã, citros (Rodrigues \& Almeida, 1998). Apesar de sua ampla utilização na agricultura, não existem parâmetros para se definir com precisão a dose a ser aplicada em diferentes solos. Normalmente, essas recomendações são feitas tomando-se por base observações empíricas, baseadas no teor de argila e matéria orgânica total. No entanto,

Recebido para publicação em 30/3/2001 e na forma revisada em 17/12/2001.

2 Doutorando, UFV, Dep. de Fitotecnia; 36571-000 Viçosa-MG; ${ }^{3}$ Mestrando, Dep. de Fitotecnia da Universidade Federal de Viçosa - UFV, 36571-000 Viçosa-MG; ${ }^{4}$ Prof. do Dep. de Fitotecnia da UFV; ${ }^{5}$ Prof. do Dep. de Química da UFV; ${ }^{6}$ Prof. do Dep. de Solos da UFV; ${ }^{7}$ Acadêmico, Dep. de Agronomia da UFV. ${ }^{8}$ Prof. do Dep. de Química da UFMG, Belo Horizonte-MG.

Planta Daninha, Viçosa-MG, v.19, n.3, p.391-400, 2001 
outros parâmetros devem ser considerados, em razão de seus efeitos na sorção do herbicida aplicado no solo, entre eles a qualidade do material orgânico, relacionado à densidade de cargas (Dunigan \& McIntosh, 1971); a quantidade do material orgânico protegido quimicamente, formando complexo argilo-orgânico (Pusino et al., 1992; Chorover et al., 1999); os tipos de minerais predominantes na fração argila (Loux et al., 1989; Cox et al., 1998); os cátions saturando o complexo de troca (Loux et al., 1989; Pusino et al., 1992); e o pH do solo (Skipper et al., 1978).

Nas condições tropicais em que os solos são altamente intemperizados, predominam óxidos e hidróxidos de $\mathrm{Fe}$ e $\mathrm{Al}$ e argilas silicatadas $1: 1$, de baixa reatividade (caulinita); desse modo, a matéria orgânica é o principal contribuinte para a CTC desses solos.

Dentre os compartimentos da matéria orgânica do solo, as substâncias húmicas são relatadas como as principais responsáveis pela sorção de herbicidas (Pusino et al., 1992; Celis et al., 1997). Apesar de apresentarem menor densidade de grupamentos funcionais em relação aos ácidos orgânicos de baixo peso molecular, são as mais estudadas, devido à sua predominância nos solos. A maior parte das substâncias húmicas, principalmente em regiões tropicais, está na forma de complexos argilo-orgânicos (52 a 98\%), segundo Stevenson (1994), cuja energia de ligação total dependerá das diferentes formas de interação promovidas pelos grupos funcionais dos componentes orgânicos. Nessa condição, seus grupamentos funcionais neutralizam-se com as cargas dos minerais de argila, o que reduz sua capacidade de sorção de herbicidas.

O objetivo deste trabalho foi avaliar a sorção de atrazine em substratos orgânico e mineral isoladamente e em misturas, visando conhecer os processos de retenção desse herbicida por algumas das principais partículas coloidais constituintes dos solos brasileiros.

\section{MATERIAL E MÉTODOS}

O atrazine utilizado neste trabalho possuía 97\% de pureza. Na Tabela 1 estão apresentadas suas características físico-químicas.

Os substratos usados nos estudos de sorção do atrazine estão descritos na Tabela 2. A caulinita de granulometria fina foi fornecida pela Mineradora Caolinita Ltda., a qual foi branqueada com ditionito, para retirada de óxidos (Mineradora Caolinita Caulin, 1989). Goethita e ferridrita foram sintetizadas seguindo a metodologia descrita por Schwertmann \& Cornell (1991). O ácido húmico foi extraído de um Organossolo Sáprico, de Arraial do Cabo RJ, seguindo a metodologia descrita por Swift (1996).

Nos estudos de sorção utilizou-se uma solução-estoque de atrazine $(1.000 \mu \mathrm{M})$ preparada a partir do padrão com $97 \%$ de pureza, em que 0,022 g do padrão foi dissolvido e diluído para $100 \mathrm{~mL}$ em metanol. Esta soluçãopadrão foi diluída com solução $0,01 \mathrm{M} \mathrm{CaCl}_{2}$, para obtenção de soluções contendo 0,$0 ; 10,0$; 20,0; 40,0; 70,0; e 100,0 $\mu \mathrm{mol} \mathrm{L}^{-1}$ de atrazine (Celis et al., 1997). A seguir, uma alíquota de $10 \mathrm{~mL}$ de cada uma dessas soluções foi adicionada aos tratamentos (substratos), previamente preparados. $\mathrm{O} \mathrm{pH}$ da solução foi ajustado para 5,1 , utilizando-se $\mathrm{HCl}$ ou $\mathrm{Ca}(\mathrm{OH})_{2}$. Para extração de atrazine não-sorvido pelos colóides, cada solução mais os substratos foram acondicionados em frascos de vidro e colocados sob agitação horizontal em banho-maria, à temperatura de $26 \pm 2{ }^{\circ} \mathrm{C}$, por 24 horas e centrifugados a $1.308 \mathrm{~g}$ por 18 minutos. O sobrenadante foi transferido para funil de separação, sendo adicionados $10 \mathrm{~mL}$ de acetato de etila - solvente (Sonon \& Schwab, 1995; McLaughlin \& Johnson, 1997). Foram realizadas duas extrações sucessivas com $10 \mathrm{~mL}$ do solvente sob agitação por dois minutos. As duas frações (fase orgânica) foram recolhidas em erlenmeyer, tendo sido adicionados aproximadamente $2 \mathrm{~g}$ de sulfato de sódio anidro, para eliminação da água. Depois disso, o sobrenadante foi transferido para um balão de fundo redondo de $100 \mathrm{~mL}$. $\mathrm{O}$ volume foi reduzido a aproximadamente $2 \mathrm{~mL}$ em evaporador rotativo. Esse volume foi transferido quantitativamente para um balão volumétrico de $5 \mathrm{~mL}$ e completado com acetato de etila. As concentrações de atrazine nas amostras foram determinadas por cromatografia gasosa. Para isso, utilizou-se cromatógrafo a gás Shimadzu, modelo GC - $17 \mathrm{~A}$, equipado com detector de ionização de chama e coluna BP-5 com fase estacionária composta por $95 \%$ de metilsiloxano e $5 \%$ de fenilsiloxano, com $30 \mathrm{~m}$, $0,25 \mathrm{~mm}$ de diâmetro interno e $1 \mu \mathrm{m}$ de espessura de filme. 
Tabela 1 - Características físico-químicas da molécula de atrazine

\begin{tabular}{|c|c|c|c|c|c|}
\hline Peso Molecular & $\begin{array}{l}\text { Solubilidade } \\
\qquad\left(\mu \mathrm{g} \mathrm{mL} L^{-1}\right)\end{array}$ & $\begin{array}{c}\text { Pressão de Vapor } \\
\left(\mathrm{mm} \mathrm{Hg} \mathrm{a} 25^{\circ} \mathrm{C}\right)\end{array}$ & $\mathrm{pKa}$ & $\begin{array}{c}\mathrm{K}_{\mathrm{ow}} \\
\text { (a } 25^{\circ} \mathrm{C} \text { ) }\end{array}$ & $\begin{array}{c}\text { Densidade } \\
\left(\mathrm{g} \mathrm{cm}^{-3} \text { a } 20^{\circ} \mathrm{C}\right)\end{array}$ \\
\hline 216 & 33 & $8,4 \times 10^{-7}$ & 1,68 & 481 & 0,363 \\
\hline
\end{tabular}

Fonte: Rahman \& Matthews (1979); Wauchoper \& Koskinen (1983); Rodrigues \& Almeida (1998).

Tabela 2 - Descrição dos tratamentos utilizados

\begin{tabular}{|l|c|}
\hline \multicolumn{1}{|c|}{ Substrato } & Quantidade (mg) \\
\hline Ácidos Húmicos & 50 \\
Caulinita (argila silicatada 1:1) & 200 \\
Goethita (óxido de Fe cristalino) & 200 \\
Ferridrita (óxido de Fe amorfo) & 200 \\
Ácidos Húmicos + Caulinita & $25+100$ \\
Ácidos Húmicos + Goethita & $25+100$ \\
Ácidos Húmicos + Ferridrita & $25+100$ \\
\hline
\end{tabular}

As condições analíticas utilizadas foram: temperatura inicial da coluna de $80{ }^{\circ} \mathrm{C}$, com elevação de $25{ }^{\circ} \mathrm{C}$ por minuto até $300{ }^{\circ} \mathrm{C}$ (15 minutos); temperatura do injetor: $250{ }^{\circ} \mathrm{C}$; temperatura do detector: $300^{\circ} \mathrm{C}$; gás de arraste: nitrogênio; volume injetado: $1 \mu \mathrm{L}$; fluxo de gás de arraste: $1,2 \mathrm{~mL}$ min. ${ }^{-1}$; e razão split: $1: 5$.

O atrazine foi quantificado comparandose as áreas dos picos das amostras dos cromatogramas com a curva de calibração, tomandose como base a concentração do atrazine na solução em equilíbrio com o substrato $\left(\mu \mathrm{g} \mathrm{mL}^{-1}\right)$. Após a quantificação do atrazine que ficou na solução em equilíbrio com o substrato, determinou-se a quantidade que ficou sorvida no solo, sendo a área da amostra igual à área do pico de atrazine determinado no cromatograma para a amostra do tratamento na concentração inicial de atrazine, e a área do padrão é igual à área do pico de atrazine determinado no cromatograma para o padrão na concentração de atrazine. Para esta determinação utilizou-se a equação $\mathrm{x} / \mathrm{m}=\mathrm{v} / \mathrm{m}\left(\mathrm{C}_{\mathrm{p}}-\mathrm{C}_{\mathrm{e}}\right)$, em que: $\mathrm{x} / \mathrm{m}=$ quantidade de atrazine sorvida por grama de solo ( $\left.\mu \mathrm{g} \mathrm{g}^{-1}\right) ; \mathrm{v}=$ volume da solução de atrazine adicionada $(\mathrm{mL}) ; \mathrm{m}=$ massa de substrato $(\mathrm{g})$; $\mathrm{C}_{\mathrm{p}}=$ concentração de atrazine na solução-padrão $\left(\mu \mathrm{g} \mathrm{mL}^{-1}\right)$; e $\mathrm{C}_{\mathrm{e}}=$ concentração de atrazine na solução em equilíbrio com o solo $\left(\mu \mathrm{g} \mathrm{mL}^{-1}\right)$.
Para interpretação do estudo da sorção de atrazine foi utilizada a equação de Freundlich, que estabelece a correlação entre a quantidade de agrotóxico adsorvido e a quantidade em solução. A partir da concentração de equilíbrio $\left(\mathrm{C}_{\mathrm{e}}\right)$ e da quantidade sorvida $(\mathrm{x} / \mathrm{m})$, determinadas experimentalmente, foram ajustadas as isotermas de sorção de Freundlich, utilizandose a equação $\mathrm{x} / \mathrm{m}=\mathrm{K}_{\mathrm{f}} \cdot \mathrm{C}_{\mathrm{e}}{ }^{1 / \mathrm{n}}$, em que $\mathrm{K}_{\mathrm{f}}=$ coeficiente de sorção; e $1 / \mathrm{n}$ = índice da intensidade da sorção, que indica o grau de linearidade da isoterma. Também foram calculados o coeficiente de adsorção $\left(\mathrm{K}_{\mathrm{d}}\right)$ observado, por meio da razão entre a quantidade de atrazine sorvida $(\mathrm{x} / \mathrm{m})$ e a quantidade de herbicida que permaneceu em solução após o período de equilíbrio $\left(\mathrm{C}_{\mathrm{e}}\right)$, e o $\mathrm{K}_{\mathrm{d}}$ esperado, que é a soma dos $\mathrm{K}_{\mathrm{ds}}$ observados dos elementos isolados em cada mistura. A eficiência de extração foi de 93,67\%.

\section{RESULTADOS E DISCUSSÃO}

Na Figura 1 observa-se o cromatograma do extrato de atrazine em acetato de etila. $\mathrm{O}$ tempo de retenção desse herbicida nas condições cromatográficas otimizadas foi de 14,42 minutos.

As isotermas de sorção foram do tipo-C, com exceção dos tratamentos goethita e goethita+ácido húmico, os quais se enquadraram no tipo-L (Figura 2), de acordo com a classificação proposta por Giles et al. (1960). Estudos têm registrado isotermas do tipo-C para sorção de $s$-triazinas em solos e substratos puros (McGlamery \& Slife, 1966; Huang et al., 1984). Esse tipo de curva denota a ocorrência de novos sítios de sorção com o aumento da concentração do herbicida. Por outro lado, o tipo-L, também encontrado por Celis et al. (1997) e Albuquerque et al. (1999), indica diminuição dos sítios de sorção com o aumento da concentração do herbicida. 


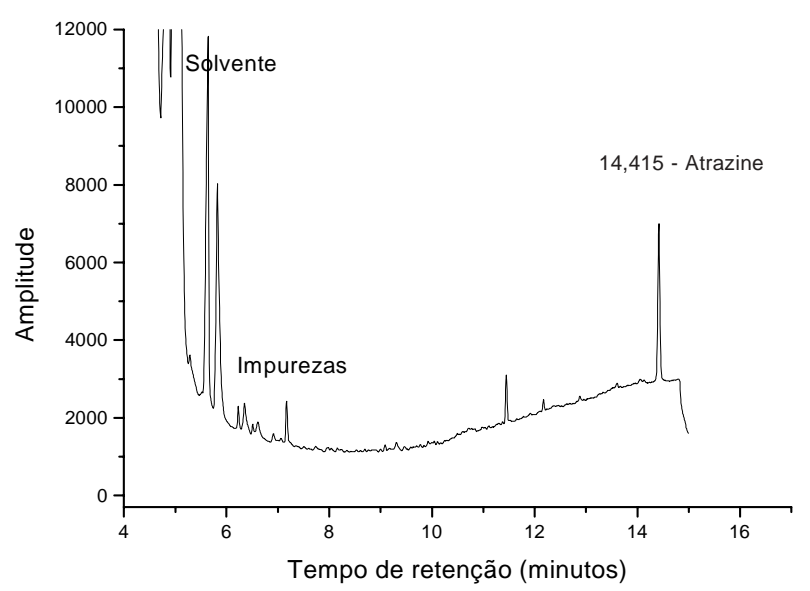

Figura 1 - Cromatograma do extrato do herbicida atrazine em acetato de etila.

Os coeficientes de Freundlich determinados, $\mathrm{K}_{\mathrm{f}}$ e $1 / \mathrm{n}$, bem como os coeficientes de determinação $\left(\mathrm{R}^{2}\right)$, estão apresentados na Tabela 3. Verifica-se que a equação de Freundlich ajusta-se adequadamente para descrever a sorção de atrazine para todos os substratos, cujos coeficientes de determinação $\left(R^{2}\right)$ variaram de 0,8025 a 0,9930. Melhor comparação entre os tratamentos pode ser visualizada tomando-se por base o coeficiente de sorção linear $\left(\mathrm{K}_{\mathrm{d}}\right)$, calculado e inserido na Tabela 3. Observa-se nesta tabela que a sorção de atrazine pelos ácidos húmicos isolados foi aproximadamente nove vezes maior do que a sorção encontrada para caulinita, goethita e ferridrita, também analisados isoladamente. Isso indica a alta afinidade entre o herbicida e os ácidos húmicos (Celis et al., 1997; MartinNeto et al., 1994).

O atrazine pode ser sorvido em colóides orgânicos por diversos mecanismos. Inicialmente, tem-se a alta densidade de sítios hidrofóbicos, aos quais a fração do atrazine nãodissociada (comportamento não-iônico) pode ligar-se. Segundo Martin-Neto et al. (1999), este seria o principal mecanismo envolvido na sorção do atrazine com substâncias húmicas. O $\mathrm{pH}$ ajustado nas soluções de equilíbrio $(5,1)$ encontra-se na faixa do pKa dos ácidos húmicos (em torno de 4,8-5,2). Dados obtidos por Senesi et al. (1996) por microscopia eletrônica indicam que valores de $\mathrm{pH}$ próximos ao $\mathrm{pKa}$ das substâncias húmicas favorecem seu formato globular, com maior conteúdo de sítios hidrofóbicos. Este pH também resulta num equilíbrio entre cargas positivas e negativas; como o atrazine é uma base fraca (pKa=1,68), nessas condições de $\mathrm{pH}$ ocorre protonação de parte de seus grupamentos (principalmente carboxílicos e fenólicos), resultando em um comportamento parcial catiônico. Nessa situação haverá elevada atração entre as moléculas de atrazine (carregadas positivamente) e os grupamentos dos ácidos húmicos que se encontram dissociados (cargas negativas). Compostos menos ácidos, como s-triazinas, podem tornarse catiônicos através de protonação. A ocorrência ou não da protonação dependerá da natureza do herbicida em questão, refletida principalmente pelo seu pKa, e do poder de suprimento de prótons dos colóides húmicos. Retenção do atrazine protonada pode também ocorrer por meio de sítios de radicais livres. Ainda pode ocorrer, segundo Stevenson (1994), sorção pela protonação direta de atrazine no colóide orgânico quando ambos, os grupamentos dos ácidos húmicos e a molécula de atrazine, não estão dissociados.

Outros mecanismos de sorção podem também estar envolvidos. Forças físicas atuam na sorção de atrazine, manifestando-se como forças de van der Waals, ocorrendo nas moléculas de atrazine não-dissociadas (não-polares), e/ou interações de transferência de cargas, que são ligações entre os anéis aromáticos do herbicida, deficientes de elétron (carga positiva), e os anéis aromáticos da matéria orgânica, ricos em elétrons (carga negativa), como suposto por alguns autores (Piccolo et al., 1992; Senesi et al., 1995). Todavia, de acordo com MartinNeto et al. (1994), a presença do átomo de cloro na posição 2 do anel de triazina atua como retirador de elétrons, inibindo a capacidade de doação de elétrons e evitando a formação de complexos de transferência de carga com substâncias húmicas. Outra possibilidade inclui pontes de hidrogênio entre o grupamento amina secundário da molécula de atrazine e os grupos $\mathrm{OH}$ ou $\mathrm{C}=\mathrm{O}$ da matéria orgânica. Por fim, podem ocorrer ligações de coordenação, em que um metal polivalente forma ponte entre o herbicida e o constituinte do solo (argila ou matéria orgânica). 

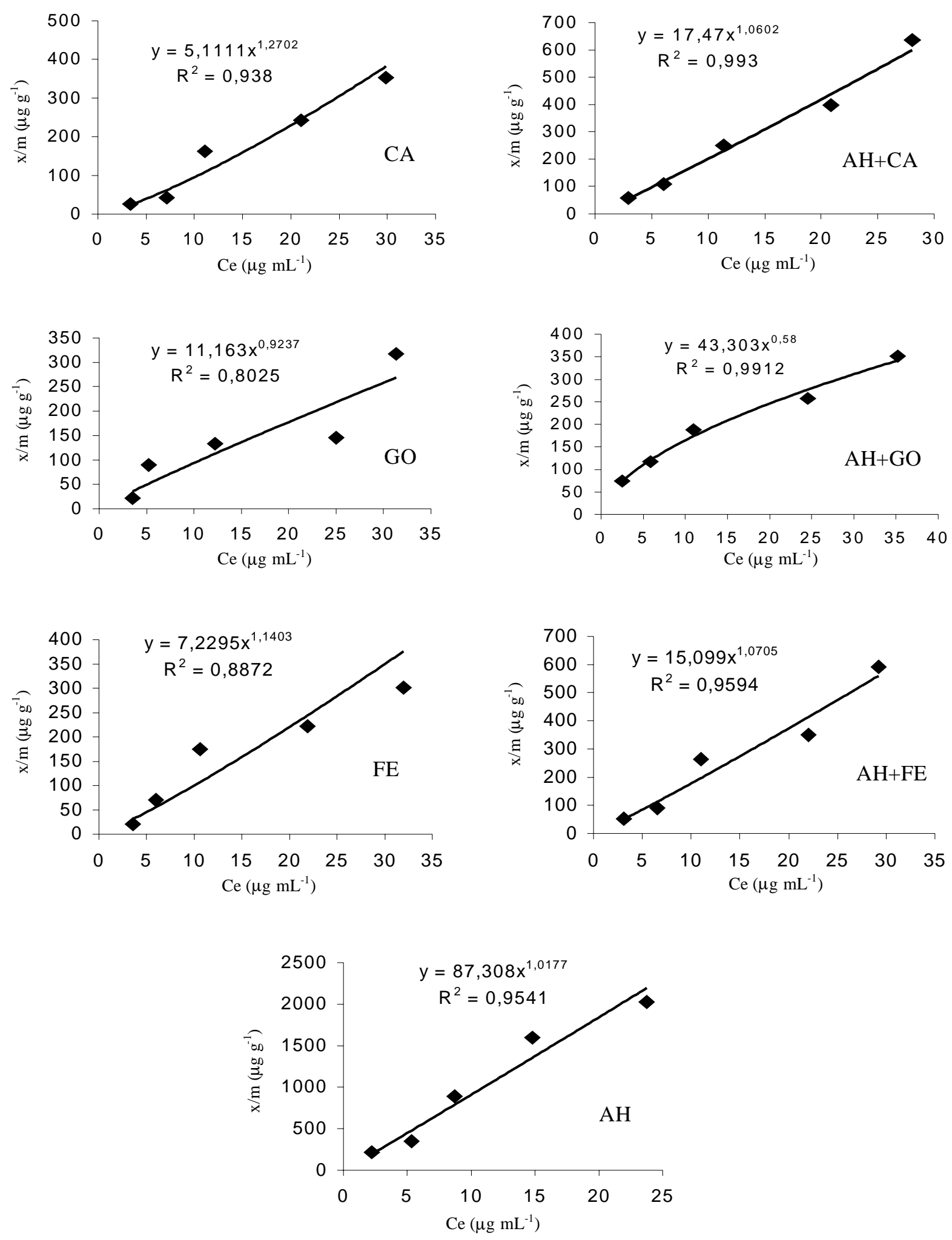

Figura 2 - Isotermas de sorção de atrazine em diferentes solventes estudados: CA (caulinita), GO (goethita), Fe (ferridrita), AH (ácidos húmicos), $\mathrm{AH}+\mathrm{CA}$ (ácidos húmicos+caulinita), $\mathrm{AH}+\mathrm{GO}$ (ácidos húmicos+goethita) e $\mathrm{AH}+\mathrm{FE}$ (ácidos húmicos+ferridrita). 
Tabela 3 - Valores das constantes de Freundlich de atrazine em alguns substratos isolados e em misturas em pH 5,1

\begin{tabular}{|l|r|c|c|c|}
\hline \multicolumn{1}{|c|}{ Substratos } & \multicolumn{1}{c|}{$\mathrm{Kf}^{\mathrm{a}}$} & $1 / \mathrm{n}^{\mathrm{a}}$ & $\mathrm{R}^{2 \mathrm{~b}}$ & $\mathrm{~K}_{\mathrm{d}}$ \\
\hline Ácidos Húmicos & 87,31 & 1,0277 & 0,9541 & 91,89 \\
Caulinita & 5,11 & 1,2702 & 0,9380 & 10,33 \\
Goethita & 11,16 & 0,9223 & 0,8025 & 10,08 \\
Ferridrita & 7,23 & 1,1403 & 0,8872 & 10,71 \\
Ácidos Húmicos + Caulinita & 17,47 & 1,0602 & 0,9930 & 18,75 \\
Ácidos Húmicos + Goethita & 43,30 & 0,5800 & 0,9912 & 17,34 \\
Ácidos Húmicos + Ferridrita & 15,10 & 1,0705 & 0,9594 & 18,15 \\
\hline
\end{tabular}
a Valores dos coeficientes de Freundlich.
b Coeficientes de determinação da isoterma de Freundlich.

A baixa sorção ocorrida na caulinita e nos óxidos de ferro (goethita e ferridrita) deve-se à baixa CTC e à baixa superfície específica (7-30, 20-30 e 200 a $300 \mathrm{~m}^{2} \mathrm{~g}^{-1}$, respectivamente para caulinita, goethita e ferridrita) apresentada por esses minerais (Shea \& Weber, 1983; Stevenson, 1994). Shea \& Weber (1983), trabalhando com o herbicida fluridone, encontraram uma sorção cerca de dez vezes maior para a matéria orgânica saturada com $\mathrm{H}$, em relação à caulinita, concordando com os resultados obtidos neste trabalho.

A falta de atração entre as formas moleculares e iônicas do herbicida por superfícies hidrofílicas foi o provável mecanismo responsável pela não-ocorrência de sorção do herbicida picloran pela caulinita, observada por Grover (1971). Esse mecanismo poderia também estar ocorrendo entre a caulinita e o atrazine.

A sorção de atrazine nos óxidos de ferro foi muito baixa, quando comparada com os ácidos húmicos. O pH da suspensão de equilíbrio $(5,1)$, na superfície dos colóides, atinge valores ao redor de duas unidades abaixo do $\mathrm{pH}$ da solução, valores estes menores que o PCZ desses óxidos $( \pm 7,0)$, os quais tendem a apresentar predominância de cargas positivas. Por ser o atrazine uma base fraca, que apresenta parte de suas cargas positivas neste $\mathrm{pH}$, isso pode resultar em repulsão de cargas, reduzindo a sorção (Borggaard \& Streibig, 1988).

Estudos de sorção realizados por Cox et al. (1998) indicaram que a sorção do imidacloprid (inseticida) é muito baixa na ferridrita $\left(\mathrm{K}_{\mathrm{d}}=0,46\right)$ e alta nos ácidos húmicos $\left(K_{d}=139\right)$.

Planta Daninha, Viçosa-MG, v.19, n.3, p.391-400, 2001
A sorção promovida por minerais de argila como caulinita, óxidos e componentes orgânicos pode variar com o cátion predominante que satura o colóide (Weber, 1980; Li \& Mortland, 1981; Pusino et al., 1992). Li \& Mortland (1981) observaram que a sorção de buthidazole em caulinita aumentou em torno de nove vezes quando o cálcio foi substituído pelo cobre que satura o colóide. Nas condições do experimento, o cátion presente na superficie do colóide foi o cálcio. Segundo Varadachari et al. (1997), trabalhando com a interação ácidos húmicos+goethita saturada com diferentes cátions, o incremento na complexação foi maior quando o cátion saturante passou de divalente para trivalente e decresceu com íons monovalentes, e a saturação da goethita com cálcio promoveu 50\% de complexação do ácido húmico, em relação ao ácido húmico isolado.

Pela Tabela 4, nota-se que a interação ácidos húmicos+caulinita resultou em um $\mathrm{K}_{\mathrm{d}}=$ $18,95 \mathrm{~mL} \mathrm{~g}^{-1}$, sendo este $62,93 \%$ menor que o $\mathrm{K}_{\mathrm{d}}$ esperado, que representa a sorção dos componentes isolados. Os complexos ácidos húmicos+goethita e ácidos húmicos+ferridrita resultaram em 65,99 e 64,63\% de redução na sorção do atrazine, em relação à sorção dos componentes isolados (Tabelas 5 e 6). Esses resultados evidenciam a interferência desses substratos na capacidade de sorção dos ácidos húmicos (Figura 3). Existem algumas hipóteses para explicar o comportamento observado. A primeira seria a ocorrência de mudanças nas propriedades dos componentes quando complexados, como redução de sítios hidrofóbicos, alteração do $\mathrm{pH}$ da superfície e redução da superfície específica, resultando em diferentes comportamentos de sorção dos complexos em relação ao esperado para os constituintes individuais. Com relação aos sítios hidrofóbicos, os ácidos húmicos isolados, em baixo $\mathrm{pH}$, apresentam estrutura mais fechada, expondo, com isso, maior número destes sítios (Martin-Neto et al., 1999). No entanto, não se sabe se o complexo ácidos húmicos-argila e/ou ácidos húmicos-óxidos apresentaria o mesmo comportamento. Como houve acentuada queda na sorção de atrazine quando os ácidos húmicos estavam complexados, uma provável hipótese para o ocorrido seria o fato de que os ácidos húmicos complexados, mesmo em baixos valores de $\mathrm{pH}$, ficariam impedidos de adquirir uma 
conformação mais fechada (globular) e, conseqüentemente, de expor grande parte de seus sítios hidrofóbicos. Pode-se concluir do exposto que a formação de complexos não bloquearia apenas sítios hidrofílicos, mas também sítios hidrofóbicos.

Tabela 4 - Efeito da interação entre ácidos húmicos e caulinita na sorção de atrazine

\begin{tabular}{|c|c|c|c|c|}
\hline $\begin{array}{l}\text { Ácidos } \\
\text { Húmicos }\end{array}$ & Caulinita & \multicolumn{2}{|c|}{$\mathrm{K}_{\mathrm{d}}$} & $\begin{array}{l}\text { Redução na } \\
\text { sorção }\end{array}$ \\
\hline \multicolumn{2}{|c|}{ (mg) } & observado & esperado & $(\%)$ \\
\hline 50 & 0 & 91,89 & 91,89 & - \\
\hline 0 & 200 & 10,33 & 10,33 & - \\
\hline 25 & 100 & 18,95 & 51,12 & 62,93 \\
\hline
\end{tabular}

Tabela 5 - Efeito da interação entre ácidos húmicos e goethita na sorção de atrazine

\begin{tabular}{|c|c|c|c|c|}
\hline $\begin{array}{l}\text { Ácidos } \\
\text { Húmicos }\end{array}$ & Goethita & \multicolumn{2}{|c|}{$\mathrm{K}_{\mathrm{d}}$} & $\begin{array}{l}\text { Redução na } \\
\text { sorção }\end{array}$ \\
\hline \multicolumn{2}{|c|}{ (mg) } & observado & esperado & $(\%)$ \\
\hline 50 & 0 & 91,89 & 91,89 & - \\
\hline 0 & 200 & 10,08 & 10,08 & - \\
\hline 25 & 100 & 17,34 & 50,99 & 65,99 \\
\hline
\end{tabular}

Tabela 6 - Efeito da interação entre ácidos húmicos e ferridrita na sorção de atrazine

\begin{tabular}{|c|c|c|c|c|}
\hline $\begin{array}{l}\text { Ácidos } \\
\text { Húmicos }\end{array}$ & Ferridrita & \multicolumn{2}{|c|}{$\mathrm{K}_{\mathrm{d}}$} & $\begin{array}{l}\text { Redução na } \\
\text { sorção }\end{array}$ \\
\hline \multicolumn{2}{|c|}{ (mg) } & observado & esperado & $(\%)$ \\
\hline 50 & 0 & 91,89 & 91,89 & - \\
\hline 0 & 200 & 10,71 & 10,71 & - \\
\hline 25 & 100 & 18,15 & 51,31 & 64,63 \\
\hline
\end{tabular}

Outro provável modo de interação dos ácidos húmicos com a fração argila envolve o bloqueio de seus grupamentos ácidos, principalmente carboxílicos e fenólicos (Pusino et al., 1992). Esses resultados corroboram os obtidos por Celis et al. (1998) e Cox et al. (1998).

Cox et al. (1998) afirmam que a matéria orgânica do solo também pode bloquear sítios da superfície de minerais de argila, principalmente 2:1, contribuindo para redução da sorção desses minerais. Como a caulinita e os óxidos de ferro utilizados neste trabalho apresentam baixa atividade, sua interferência é maior sobre os sítios da matéria orgânica do que desta sobre aqueles.

Alguns mecanismos podem ser responsáveis pela sorção não-linear encontrada para o atrazine no tratamento ácidos húmicos+ goethita (Figura 2). O primeiro é o decréscimo da disponibilidade de sítios com o aumento da sorção. Outro fator refere-se ao tipo de sítio de sorção. Moléculas orgânicas tendem a ser sorvidas primeiramente por sítios de alta energia (mais estáveis), seguidos progressivamente por sítios de menor energia (menos estáveis) (Sonon \& Shwab, 1995).

Apesar de a ferridrita apresentar superfície específica cerca de 7-10 vezes maior que a goethita, observa-se que ambos os óxidos de ferro interferiram de forma similar na sorção de atrazine quando complexado com ácidos húmicos - 65,99 e 64,63\% para goethita e ferridrita, respectivamente (Tabelas 5 e 6). Isto pode ser devido, segundo Varadachari et al. (1997), ao fato de o grau da fixação de óxidos de ferro e ácidos húmicos não estar relacionado com a superfície específica ou com o PCZ destes. Celis et al. (1998) verificaram que a eficiência da sorção de atrazine pelo ácido húmico decresceu com a associação com ferridrita, sugerindo que esta associação reduz a disponibilidade de grupos funcionais para sorção de atrazine.

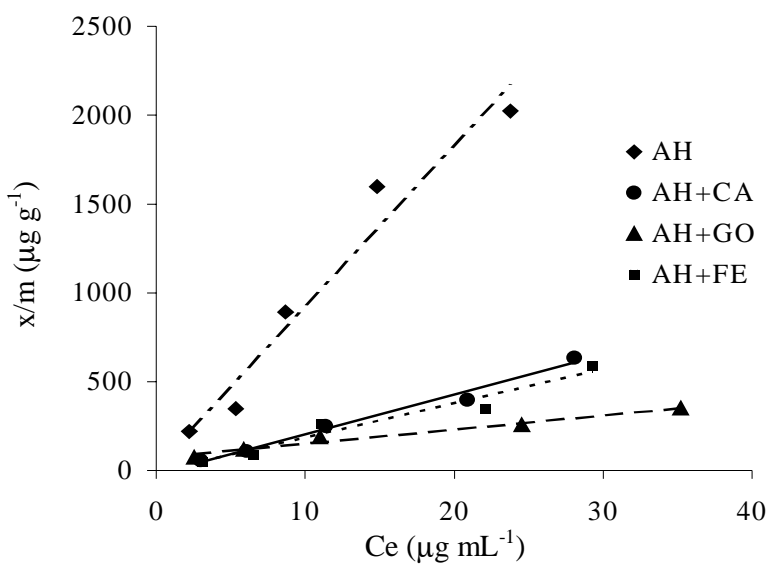

Figura 3 - Efeitos das interações entre ácidos húmicos e sorventes minerais na sorção de atrazine: AH (ácidos húmicos), $\mathrm{AH}+\mathrm{CA}$ (ácidos húmicos+caulinita), $\mathrm{AH}+\mathrm{GO}$ (ácidos húmicos+goethita) e $\mathrm{AH}+\mathrm{FE}$ (ácidos húmicos+ferridrita).

Planta Daninha, Viçosa-MG, v.19, n.3, p.391-400, 2001 
De acordo com Varadachari et al. (1997) e $\mathrm{Gu}$ et al. (1994), a troca de ligantes seguida por pontes de hidrogênio e pontes catiônicas são os mecanismos de sorção preponderantes entre as substâncias húmicas e as superfícies hidroxiladas. Em óxidos de ferro sintetizados, como a goethita, Varadachari et al. (1997) observaram que a forma de ligação destes com os ácidos húmicos pode ser tanto por meio de pontes de cátion como por meio de reações de coordenação diretamente nos sítios hidroxilados; pode ainda, segundo Fontes (1990), ser por troca de ligantes. Kaiser et al. (1997), através de espectroscopia, verificaram a importância de grupos carboxílicos e estruturas aromáticas na sorção de ácidos húmicos em óxidos naturais e sintéticos.

Varadachari et al. (1997) inferem que a fixação dos ácidos húmicos pela goethita reduz com o incremento do $\mathrm{pH}$, em virtude de as concentrações de prótons na superfície encontrarem-se não-disponíveis para formação de pontes de hidrogênio entre o ácido e o óxido. $\mathrm{O}$ tempo de interação entre os substratos foi de 24 horas. Pode-se supor que um aumento nesse tempo incrementaria a complexação dos solventes, potencializando o bloqueio dos sítios de sorção do atrazine. Os dados encontrados para o $K_{d}$ de cada substrato indicam que solos com predominância de caulinita e óxidos de ferro e alumínio na fração argila e baixos teores de matéria orgânica são mais propensos à lixiviação de herbicidas e conseqüente contaminação de águas subterrâneas.

A quantificação do teor de matéria orgânica do solo em análises de rotina determina parte da matéria orgânica complexada com os minerais de argila. Essa fração, como observada neste trabalho, participa muito pouco na sorção do atrazine, bem como de outros herbicidas utilizados, superestimando, desse modo, a dose recomendada com base no teor de matéria orgânica desses solos. Além disso, recomendações baseadas apenas na quantidade da matéria orgânica não consideram sua qualidade (polaridade e densidade de cargas).

A predominância de minerais de argila e óxidos/hidróxidos de ferro de baixa atividade pode prejudicar a capacidade de sorção dos compostos orgânicos do solo, ao contrário das pressuposições técnicas/práticas que lhes atribuem elevada contribuição para sorção de herbicidas. Dessa forma, excluindo-se as propriedades físicas do solo, um modelo correto na determinação da dose dos herbicidas aplicados ao solo deveria incorporar variáveis como: teor, qualidade e quantidade de matéria orgânica complexada com a fração argila e pH do solo. Sugere-se ainda que trabalhos dessa natureza sejam realizados com solos representativos e herbicidas mais utilizados no País, visando recomendações de uso mais precisas.

\section{AGRADECIMENTOS}

A Karine Almeida Lage, Cristina Schetino Bastos, e José Fábio França Orlanda, pela imprescindivel contribuição durante a realização desta pesquisa.

\section{LITERATURA CITADA}

ALBUQUERQUE, M.A.; FOLONI, J.M.; SCHAEFER, C.E.; FONTES, L.E.; KER, J.C. Adsorção e dessorção de atrazine em Latossolo Roxo. R. Ci. Funel, v.2, p.51-58, 1999.

BORGGAARD, O.K.; STREIBIG, J.C. Chlorsulfuron adsorption by humic acid, iron oxides, and montmorillonite. Weed Sci., v.36, p.530-534, 1988.

CELIS, R.; COX, L.; HERMOSIN, M.C.; CORNEJO, J. Sorption of triazafluron by iron and humic acid-coated montmorillonite. J . Environ. Qual., v.26, p.472-479, 1997.

CELIS, R.; CONEJO, J.; HERMOSÍN, M.C.; KOSKINEN, W.C. Sorption of atrazine and simazine by model associations of soil colloids. Soil Sci. Soc. Am J ., v.62, p 165-171, 1998.

CHOROVER, J.; AMISTADI, M.K.; BURGOS, W.D.; HATCHER, P.G. Quinoline sorption on kaolinite - humic acid complexes. Soil Sci. Soc. Am. J ., v.63, p 850-857, 1999.

COX, L.; KOSKINEN, W.C.; CELIS, R.; YEN, P.Y.; HERMOSIN, M.C.; CORNEJO, J. Sorption of imidacloprid on soil clay mineral and organic components. Soil Sci. Soc. Am. J ., v.62, p.911915, 1998.

DUNIGAN, E.P.; McINTOSH, T.H. Atrazine-soil organic matter interactions. Weed Sci., v.19, p.279-281, 1971. 
FONTES, M.R. Interactions of goethite and humic acid in some oxisols from Brazil. Raleigh: North Caroline State University, 1990. 75p. Thesis(Ph.D.)- North Caroline State University, 1990.

GILES, C.H.; McEVANS, T.H.; NAKHWA, S.N.; SMITH, D. Studies in adsorption. Part XI. A system of classification of solution adsorption isotherms, and its use in diagnosis of adsorption mechanisms and in measurement of specific surface area of solids. J. Chem. Soc., v.111, p.3973-3993, 1960.

GROVER, R. Adsorption of picloram by soil colloids and various other adsorbents. Weed Sci., v. 19, p.417-418, 1971 .

GU, B.; SCHMITT, J.; CHEN, Y.; LANG, L.; McCARTHY, J.F. Adsorption and desorption of natural organic water on iron oxides: mechanism and models. Environ Sci. Technol., v.28, p.3846, 1994.

HUANG, P.M.; GROVER, R.; McKERCHER, R.B. Components and particle size fractions involved in atrazine adsorption by soil. Soil Sci., v.138, p.20-24, 1984.

KAISER, K.; GUGGENBERGER, G.; HAUMAIER, L.; $\mathrm{ZECH}, \mathrm{W}$. Dissolved organic matter sorption on subsoils and minerals studied by ${ }^{13} \mathrm{C}-\mathrm{NMR}$ and DRIFT spectroscopy. Europ J . Soil Sci., v.48, p.301-310, 1997.

LI, S.W.; MORTLAND, M.M. Interactions of buthidazole with clay minerals and soils. Weed Sci., v.29, p.667-671, 1981.

LOUX, M.M.; LIEBL, R.A.; SLIFE, F.W. Adsorption of clomazone on soils, sediments, and clays. Weed Sci., v.37, p.440-444, 1989.

MARTIN-NETO, L.; VIEIRA, M.E.; SPOSITO, G. Mechanism of atrazine sorption by humic acid: a spectroscopy study. Environ. Sci. Technol., v.28, p.1867-1873, 1994.

MARTIN-NETO, L.; FERREIRA, J.A.; NASCIMENTO, O.R.; TRAGHETTA, D.G.; VAZ, C.M.P.; SIMÕES, M.L. Interação herbicidas e substâncias húmicas: estudos com espectroscopia e polarografia. In: ENCONTRO BRASILEIRO SOBRE SUBSTÂNCIAS HÚMICAS, 3, 1999, Santa Maria, RS. Anais... Santa Maira: 1999. p. 13-20.
McGLAMERY, M.D.; SLIFE, F.W. The adsorption and desorption of atrazine as affected by $\mathrm{pH}$, temperature, and concentration. Weeds, v.14, p.237-239, 1966.

McLAUGHLIN, R.A.; JOHNSON, B.S. Optimizing recoveries of two chlorotriazine herbicide metabolites and 11 pesticides from aqueous samples using solid-phase extraction and gas chromatography-mass spectrometry. J . Chrom. A., v.790, p.161-167, 1997.

MINERADORA CAOLINITA Caulin. Ubá: 1989. 34p. (Informe Técnico)

PICCOLO, A.; CELANO, G.; De SIMONE, C. Interactions of atrazine with humic substances of different origins and their hydrolyzed products. Sci. Total Environ., v.117/118, p.403-412, 1992.

PUSINO, A.; LIU, W.; GESSA, C. Influence of organic matter and its clay complexes on metolachlor adsorption on soil. Pestic. Sci. v.36, p.283-286, 1992.

RAHMAN, A.; MATTHEWS, L.J. Effect of soil organic matter on the phytotoxicity of thirteen $s$-triazine herbicides. Weed Sci., v.27, p.158-161, 1979.

RODRIGUES, B.N.; ALMEIDA, F.S. Guia de herbicidas. 4.ed. Londrina: 1998. 648p.

SENESI, N.; D’ORAZIO, V.; MIANO, T.M. Adsorption mechanisms of $s$-triazine and bipyridylium herbicides on humic acids from top field soils. Geoderma, v.66, p.273-283, 1995.

SENESI, N.; RIZZI, F.R.; DELLINO, P.; ACQUAFREDDA, P. Fractal dimension of humic acids in aqueous suspension as a function of pH and time. Soi Sci. Soc. Am. J ., v.60, p.17731780, 1996.

SHEA, P.S.; WEBER, J.B. Fluridone adsorption on mineral clays, organic matter, and modified Norfolk Soil. Weed Sci., v.31, p.528-532, 1983.

SCHWERTMANN, U.; CORNELL, R.M. Iron oxides in the laboratory - Preparation and characterization. Weinheim: Verlagsgesells chat, 1991. 137p.

SKIPPER, H.D.; VOLK, V.V., MORTLAND, M.M., RAMAN, K.V. Hydrolysis of atrazine on soil colloids. Weed Sci., v.26, p.46-51, 1978. 
SONON, L.S.; SCHWAB, A.P. Adsorption characteristics of atrazine and alachlor in Kansas soils. Weed Sci., v.43, p.461-466, 1995.

STEVENSON, F.J. Humus chemistry. Genesis, composition, reactions. 2.ed. New York: John Willey \& Sons, 1994. 443p.

SWIFT, R.S. Organic matter characterization. In: SPARKS, D.L., ed. Methods of soil analysis. Part 3. Chemical methods. Madison: Soil Science Society of Americam, 1996. p.10181020, 1996.
VARADACHARI, C.; CHATTOPADHYAY, T.; GHOSCH, K. Complexation of humic substances with oxides of iron aluminum. Soil Sci., v.162, p.28-34, 1997.

WAUCHOPER, D.; KOSKINEN, W.C. Adsorptiondesorption equilibria of herbicides in soil: a thermodynamic perpective. Weed Sci., v.31, p.504-512, 1983.

WEBER, J.B. Adsorption of buthidazole, VEL 3510, tebuthiuron, and fluridone by organic matter, montmorillonite clay, exchange resins, and a sandy loam soil. Weed Sci., v.28, p.478-483, 1980. 